\title{
Aortic valve replacement in octogenarians: performance analysis of EuroSCORE II
}

\author{
D Hernandez-Vaquero ${ }^{*}$, R Diaz, JC Llosa \\ From 23rd World Congress of the World Society of Cardio-Thoracic Surgeons \\ Split, Croatia. 12-15 September 2013
}

\section{Background}

EuroSCORE has been proposed to identify patients at high risk for surgical aortic valve replacement and estimate for them the risk-benefit of percutaneous implantation. However, it has been clearly demonstrated that this system overestimates mortality, particularly in the elderly population undergoing surgery for aortic valve replacement. An actualized model called EuroSCORE II has been recently proposed to predict mortality after cardiac surgery but it has not been validated yet in the elderly population undergoing aortic valve replacement. We aimed to validate the new risk model in an octogenarian population who underwent surgery for aortic valve replacement in our center.

\section{Methods}

From March 2005 to March 2013, 378 consecutive octogenarian patients underwent aortic valve replacement in our center. Calibration (Hosmer-Lemeshow test and risk-adjusted mortality ratio) and discrimination (area under the receiver-operating characteristic curve) were calculated to assess the capacity of EuroSCORE II to predict 30-day mortality. Moreover, the same analysis was made in a subgroup of patients who underwent isolated aortic valve replacement.

\section{Results}

Observed mortality was $8,7 \%$ in the overall population and the predicted mortality by EuroSCORE II was $6,31 \%$ so that it underestimated the real mortality rate. However, the general calibration assessed by Hosmer-Lemeshow test was not bad $(\mathrm{p}=0,15)$ and the discriminatory power was very good $(C$-Statistic $=0,90)$. Assessing calibration by quartiles of risk, an adequate predictive power was

\footnotetext{
* Correspondence: dhvaquero@gmail.com

Cardiac Surgery Department, Central University Hospital of Asturias, Oviedo, Spain
}

C 2013 Hernandez-Vaquero et al; licensee BioMed Central Ltd. This is an Open Access article distributed under the terms of the Creative Commons Attribution License (http://creativecommons.org/licenses/by/2.0), which permits unrestricted use, distribution, and reproduction in any medium, provided the original work is properly cited.

\section{and take full advantage of:}

- Convenient online submission

- Thorough peer review

- No space constraints or color figure charges

- Immediate publication on acceptance

- Inclusion in PubMed, CAS, Scopus and Google Scholar

- Research which is freely available for redistribution 